\title{
Bone Marrow Mononuclear Cell Extraction. Does the Operator Performance Affect Processing Efficacy?
}

\author{
Jakobsons Eriks ${ }^{2,3}$, Cakstina Inese ${ }^{2}$, Erglis Kristaps ${ }^{2}$, Erglis Martins ${ }^{2}$, Pirtniece Liene ${ }^{2}$, Elina Krumina ${ }^{2}$, Narbute \\ Inga $^{1,3}$, Briede Ieva $^{1}$, Jegere Sanda ${ }^{1,3}$, Smolova Rita $^{1}$, Muiznieks Indrikis ${ }^{4}$ and Erglis Andrejs ${ }^{1,3}$ \\ 1. Latvian Centre of Cardiology, Pauls Stradins Clinical University Hospital Riga, LV-1002, Latvia \\ 2. Cell Transplantation Centre, Pauls Stradins Clinical University Hospita,l Riga, LV-1002, Latvia \\ 3. Research Institute of Cardiology, University of Latvia, Riga, LV-1586, Latvia \\ 4. Department of Biology, Division of Microbiology and Biotechnology, University of Latvia, Riga, LV-1586, Latvia
}

\begin{abstract}
Different cell populations from bone marrow are used in various clinical trials for cardiac diseases during last decade. Four clinical studies are on going in our institution and enrol patients with cardiac diseases, coronary disease and type 2 diabetes, patients with osteoarthritis. Density gradient is used to separate bone marrow mononuclear cells. Cell processing looses are significant. To find out critical control points we analysed processing process and differences in cell yields between operators performing cell extraction. Bone marrow mononuclear cells were isolated using Ficoll density gradient centrifugation. Cells were counted using flow cytometry for mononuclear cell total counts, CD34+ population count and viability analysis. The patients who underwent bone marrow aspiration followed by cell isolation received cell suspension for transplantation. Two cells processing for separate patients were performed at once. Same standard operation procedures were applied. Processing looses between operators performing cell extraction were analysed. Bone marrow samples from eight patients were processed. Mononuclear cells were extracted. Operator performances were compared. Operator A average bone marrow mononuclear cell yield in starting material was 9,97 \pm 9,98\%, CD34+ population yield $75,46 \pm 79,67 \%$. Operator B average bone marrow mononuclear cell yield in starting material was $24,68 \pm 14,8 \%$, CD $34+$ population yield 70,42 $\pm 44.84 \%$. Operator A average cell viability in starting material was 45,24 $\pm 9,55 \%$, after cell processing $42,96 \pm 23,66 \%$. Operator B average cell viability in starting material was $49,85 \pm 5,48 \%$, after cell processing $69,52 \pm 6,65 \%$.
\end{abstract}

Key words: Bone marrow, mononuclear cells, cell yield, cell extraction, cell count

\section{Abbreviations}

$\begin{array}{ll}\text { BM } & \text { bone marrow; } \\ \text { MNC } & \text { mononuclear cell }\end{array}$

\section{Introduction}

Different cell types are evaluated for their regenerative potential and therapeutic applicability for cardiac tissue regeneration. Studies are focusing on the use of cells isolated from bone marrow, peripheral blood, skeletal muscle, adipose tissue and umbilical cord, all of which have shown to improve cardiac function in animal models [1-3]. Amongst possible cell sources autologous bone marrow derived

Corresponding author: Erglis Andrejs, Prof., M.D., Ph.D., research fields: biology, microbiology and biotechnology. mononuclear cells (BM-MNC) and their subpopulations are most extensively being tested in clinical trials [4-6].

Many unresolved questions concerning cell transplantation still exist including the exact mechanism of the beneficial effect of cell transplantation, the optimal transport of cells into the myocardium, the type and amount of cells implanted, the timing of transplantation, the assessment of responsiveness of individual patients to the cell therapy, and the amount of transplanted cells required to achieve a significant myocardial regeneration [7].

BM-MNC isolation methods are well established; manual or automated processing is performed to produce cell suspensions for transplantation. Currently different cell delivery methods are employed in clinical 
praxis, including intracoronary injection and intramyocardial injection. The questions remaining unanswered yet are effective dose of transplanted cells and best timing for cell transplantation [8-10].

Numbers of transplanted BM-MNCs varies among clinical trials $[11,12]$ and there is little known about cell isolation and CD34+ enrichment efficacy during processing of bone marrow aspirate. In this study we compared BM-MNCs yields between operators performing cell processing and if it has effect on cell isolation efficiency.

\section{Materials and Methods}

\subsection{Bone Marrow Harvesting and Cell Preparation}

Bone marrow mononuclear cells were harvested by iliac crest puncture performed under local anaesthesia. For adult patients a 38 to $45 \mathrm{ml}$ of bone marrow was aspirated into heparin pre-filled syringes $(500 \mathrm{U} / \mathrm{ml}$ of bone marrow aspirate). The bone marrow aspirate was shipped at room temperature to the central cell-processing laboratory and further processed under Good Manufacturing Practice. In short, aspirate was diluted with sterile $0.9 \% \mathrm{NaCl}$ (1:5) (BBraun), filtrated through $100 \mu \mathrm{m}$ cell strainer (BD Biosciences), and bone marrow mononuclear cells (BM-MNCs) were isolated and enriched by density gradient with the use of Ficoll-Paque Premium (GE Healthcare Ltd.) according to manufacturers instruction, with minor protocol modifications.

Two biotechnologists at least to minimise risks of faults and ensure minimal processing time perform bone marrow processing. All activities, timing, used reagents, batch numbers, shelf life and personnel involved recorded to bone marrow processing file. Each processing is documented in detail and is coded with specific identifier to ensure processing traceability.

Processing starts with workplace preparation. Two laminar hoods are switched on. Laminar hood sash closed and UV sterilisation for $10 \mathrm{~min}$. applied. Laminary hood air cascade switched on and after airflow stabilisation wiped with disinfectant agent. Sterile instruments, disposable materials, racks and liquid waste containers placed in hood. Reagents before placing in laminary hood are checked if shelf life is valid and if container sealing is intact. For each separate bone marrow processing intact reagent containers are used.

Centrifuges are wiped with disinfectant agent and switched on. Senior biotechnologist make certain if sterile room ventilation cascade is working according to present parameters. Air microbiological conditions are checked by routine microbiological air monitoring program. Head of laboratory make certain if procedures of work place preparation are performed according to standard operation procedure and authorize processing.

Bone marrow aspirate is shipped at room temperature in marked transport container. By receiving $\mathrm{BM}$ sample biotechnologist check sample coding and record incoming biological material file. BM sample is forwarded to laminar hood using incoming material route. Before placing BM and reagents container in laminar biotechnologist wipes containers with antibacterial agent. Special attention should be applied to container lids.

Prepare 1 L 0,9\% sodium chloride and heparin solution, end concentration $10 \mathrm{U} / \mathrm{ml}$ of heparin. Mark container with container opening date and heparin concentration.

Divide BM sample in 6 separate $50 \mathrm{ml}$ Falcon centrifugation tubes. Samples transfer with $10 \mathrm{ml}$ sterile serological pipette. Add sodium chloride and heparin solution to reach $30 \mathrm{ml}$ volume in each Falcon tube. Place in laminar 6 separate $50 \mathrm{ml}$ Falcon centrifugation tubes marked with „F” for filtration. Samples filtrate using $100 \mu \mathrm{m}$ cell strainers. Place the cell strainer in the Falcon tube. Use sterile $25 \mathrm{ml}$ serological pipette to place BM solution on strainer. Used cell strainers remove to solid waste container. If filtration is interfered by blood cloths or bone debris, replace cell strainer with new. 
For initial cell count analysis $10 \mu$ l of filtrated solution was diluted in $990 \mu \mathrm{l} 0,9 \%$ sodium chloride solution. Sterile filter containing micropipette tip was used to take sample.

Fill $15 \mathrm{ml}$ of Ficoll-Paque Premium in 6 separate 50 $\mathrm{ml}$ Falcon centrifugation tubes. To remove excess ficol drops on tube walls do centrifugation of tubes for $1 \mathrm{~min}$ at $600 \mathrm{x}$.

The $25 \mathrm{ml}$ serological pipette used to pour BM solution on density gradient layer. Falcon centrifugation tube placed in 45-degree angle to laminar work place surface. The slowest discharge speed applied to minimise risks of density gradient and $\mathrm{BM}$ solution mixing. BM solution discharged on Falcon tube wall approximately $5 \mathrm{~cm}$ from ficoll surface. When $15 \mathrm{ml}$ of solution discharged Falcon tube is slowly turned to 90-degree angle position. Pouring of BM solution on density gradient should not exceed 20min for all tubes.

Present centrifugation speed $800 \mathrm{x} \mathrm{g,} 25$ minutes, + $21{ }^{\circ} \mathrm{C}$ temperature, turn off centrifuge brake mode. Make sure if all tubes contain the same volume of sample, place tubes symmetric and start centrifugation.

After centrifugation 3 fractions were formed-top plasma phase, interphase containing mononuclear cells and lower phase containing mostly erythrocytes and thrombocytes.

Part of plasma phase was slowly removed by serological pipette. Pipette tip was dipped in top layer of plasma phase and followed as level drops. Slowest suction mode was applied to minimise liquid turbulences that can disturb integrity of buffy coat. Approximately $7 \mathrm{ml}$ of plasma phase was left in tube. Removed plasma was discharged to liquid waste container.

The $10 \mathrm{ml}$ serological pipette was used to remove buffy coat. Slowest suction mode was applied. Pipette tip was dipped down to ficol layer and slowly moved over ficol surface like carpet vacuuming. Up to $7 \mathrm{ml}$ of cell containing fraction form each tube was transferred to sterile tube. Tubes containing cell fraction were filled with $0,9 \%$ sodium chloride and heparin solution up to $50 \mathrm{ml}$ total volume. Sample tubes were closed and mixed by few times gently turning upside down.

Centrifugation followed by $800 \mathrm{x}$ g, $20 \mathrm{~min}$, temperature $+21{ }^{\circ} \mathrm{C}$, centrifugation starting speed and brake on maximum.

After centrifugation supernatant was removed and pellet resuspended in $0,9 \%$ sodium chloride and heparin solution up to $50 \mathrm{ml}$ total volume.

Centrifugation followed by $600 \mathrm{x} \mathrm{g}, 20 \mathrm{~min}$, temperature $+21{ }^{\circ} \mathrm{C}$, centrifugation starting speed and brake on maximum.

After centrifugation supernatant was removed and pellet resuspended in $0,9 \%$ sodium chloride solution without heparin up to $50 \mathrm{ml}$ total volume.

Centrifugation followed by $600 \mathrm{x} \mathrm{g}, 20 \mathrm{~min}$, temperature $+21{ }^{\circ} \mathrm{C}$, centrifugation starting speed and brake on maximum.

After centrifugation supernatant was removed and $1 \mathrm{ml}$ left in each centrifugation tube. Pellet was resuspended in left supernatant. The $10 \mathrm{ml}$ sterile serological pipette was used to unite all samples in one and add $0,9 \%$ sodium chloride solution up to $15 \mathrm{ml}$. Mark tube as final material.

For final cell count analysis $250 \mu \mathrm{l}$ of cell solution was aliquoted. Sterile filter containing micropipette tip was used to take sample.

Final cell solution was filtrated using $100 \mu \mathrm{m}$ cell strainers. After filtration solution was filled in sterile container and packed in sterile secondary package and marked.

Facility authorised person make sure if processing comply with standard operation procedure and sign permit to release product for application.

Biotechnologist forward cell count samples for testing.

\subsection{Flow Cytometry}

Samples from BM and final product (BM-MNCs) were counted and used for flow cytometric analysis within $2 \mathrm{~h}$ after preparation. Stem kit from Beckman 
Coulter was used for cell labeling with CD45-FITC, CD34-PE, 7-AAD and Stem-Count fluorospheres. Cells were analysed using FC-500 (Beckman Coulter). Analysis protocol was developed manually. Stem CXP program was used for MNC, CD34+ cell count and cell viability detection. Gating was performed according to ISHAGE protocol according to manufacturer suggestion. Cell viability was obtained using 7AAD method that is included in ISHAGE protocol (Keeney et al., 1998). Each measurement contained at least 50,000 events. Maximum number of events was 100, 000. Obtained numbers of cells $/ \mu \mathrm{L}$ were calculated for total number of $\mathrm{MNC}$ and $\mathrm{CD} 34+$ cells within transplantation material. Measurements with less than 50,000 events were excluded.

\section{Results}

Bone marrow mononuclear cells were harvested by iliac crest puncture performed under local anaesthesia. All samples contained $43 \mathrm{ml}$ of bone marrow solution. Four pairs of BM processing were performed. Separate work places and equipment were used. Same standard operation procedures were applied for all processed bone marrow samples. Each final cell solution was released for clinical application. Start and final product cell counts were analysed by flow cytometry (see Table 1).

\section{Discussion}

Due to ease of harvesting bone marrow is most convenient source of MNCs applicable for both acute and chronic diseases. Processing of bone marrow in order to isolate the mononuclear cell fraction is associated with cell loss. Some studies, investigating human bone marrow processing, show BMNC recovery rates between 15 to $30 \%$ after ficoll density gradient centrifugation. Processing has a major impact on the cell counts, viability and functional activity of bone marrow derived progenitor cells. The assessment of cell counts and viability may not entirely reflect the functional quality of cells in clinical application. Some groups suggested that controversial clinical effects in large-scale clinical trials are due to technological differences in cell processing and BMNC composition [13]. In fact, it has been proven that efficacy and functionality of BMNCs are significantly influenced by red blood cell by the contamination, the content of apoptotic cells, differences in washing steps and centrifugation speed. In this study we focus on bone marrow derived mononuclear cell yields obtained from eight BM processing that were performed using same methodology for all patients.

Loses of therapeutically effective cell populations during all steps of density gradient separation negatively correlates with red blood cell and granulocyte

Table 1 Cell counts starting BM processing and after processing. Comparison of operator's performance.

\begin{tabular}{llllllll}
\hline No. & Operator & Start cell count mln & Final cell count mln & Yield \% & Start cell count mln & Final cell count mln & Yield \% \\
\hline & Operator & A & A & & B & B \\
\hline 1. & MNC & 551.00 & 80.56 & 14.62 & 55.00 & 23.50 & 42.73 \\
& CD34+ & 1.03 & 1.88 & 182.52 & 0.25 & 0.29 & 116.00 \\
& Viability \% 53.49 & 70.01 & & 41.86 & 65.98 & \\
2. & MNC & 485.00 & 0.80 & 0.16 & 138.00 & 13.40 & 9.71 \\
& CD34+ & 0.21 & 0.00 & 0.00 & 1.46 & 0.32 & 21.58 \\
& Viability \% 40.60 & 12.70 & & 50.73 & 62.58 & 15.97 \\
3. & MNC & 255.00 & 8.61 & 3.38 & 253.00 & 40.40 & 44.10 \\
& CD34+ & 0.21 & 0.07 & 33.33 & 1.61 & 0.71 & 76.92 \\
\\
Viability \% 34.00 & 40.90 & & 52.94 & 49.40 & 30.31 \\
4. & MNC & 96.30 & 20.90 & 21.70 & 163.00 & 0.82 & 100.00 \\
& CD34+ & 1.14 & 0.98 & 85.96 & 0.82 & 72.60 & \\
\hline
\end{tabular}


contamination that probably can cause unwanted clinical effects in order to get higher cell yields.

Studies describing the BMNC clinical applications use BMNC processing methods vary considerably from study to study and are not fully described. General standard operation procedures for cell extraction are not established till now. These differences may result in inconsistencies that may affect study clinical outcomes [7].

Many factors can influence material quantitative and functional quality and the study result comparisons are difficult. Factors that could affect the cell processing outcome is associated with bone marrow extraction: instruments used - aspiration needle specification (side holes, diameter), aspiration needle placement (depth, angle, radio control used), the applied negative pressure, administration of anticoagulation agents, peripheral blood volume in the sample, as well as the patient individual specificities - iliac crest thickness and internal lumens (varies depending on age, gender and health conditions). Despite factors mentioned above each individual operator performance can influence quantitative and functional quality of cell preparation for clinical application.

Results obtained in this study clearly show differences in processing efficacy (Figs. 1 and 2.)

Both operators are experienced-operator A have processed more than $140 \mathrm{BM}$ samples in period of seven

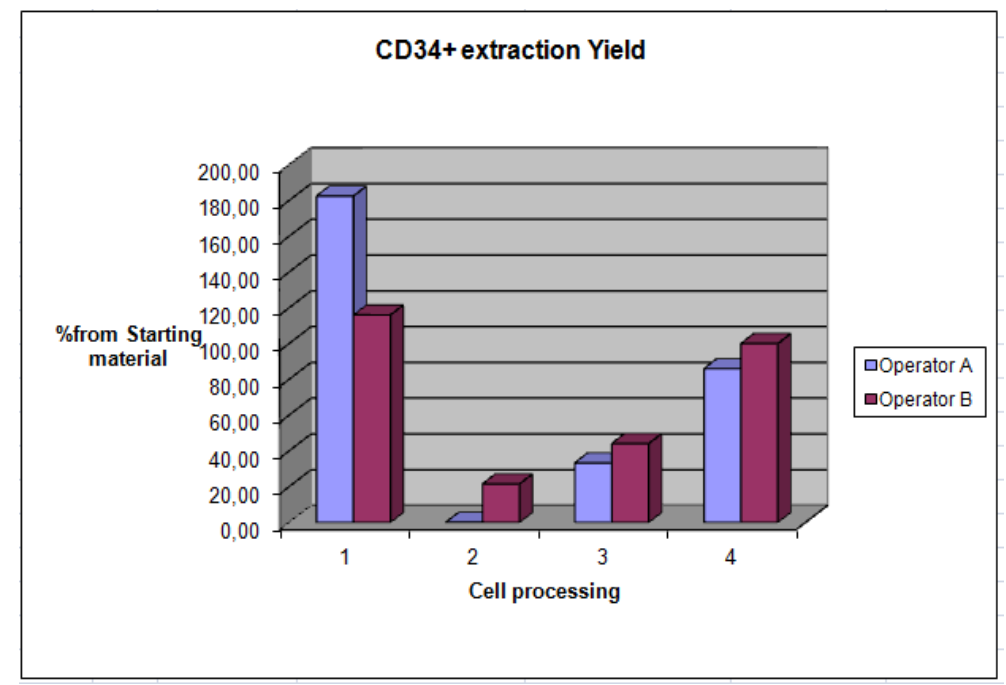

Fig. 1 CD34+ population extraction yield. Operator A and B performance comparison.

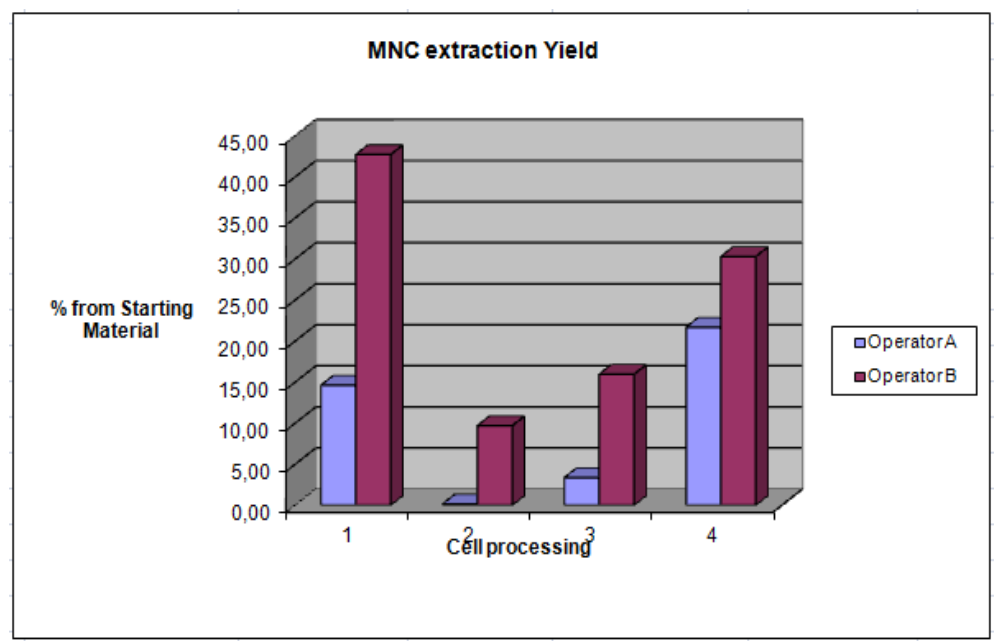

Fig. 2 Mononuclear cell population extraction yield. Operator A and B performance comparison. 
Table 2 Average MNC and CD34+ population yields and standard deviation.

\begin{tabular}{lllll}
\hline & MNC & StDev & CD34+ & StDev \\
\hline Operator A & 9.97 & 9.98 & 75.46 & 79.67 \\
Operator B & 24.68 & 14.80 & 70.42 & 44.84 \\
\hline
\end{tabular}

Table 3 Average cell viability of starting /final material and standard deviation.

\begin{tabular}{lllll}
\hline & & Operator A & \multicolumn{2}{c}{ Operator B } \\
\hline & Start & Final & Start & Final \\
\hline Average viability & 45.24 & 42.96 & 49.85 & 69.52 \\
StDev & 9.55 & 23.66 & 5.48 & 6.45 \\
\hline
\end{tabular}

years. Operator B has performed more than $50 \mathrm{BM}$ processing during two years. Comparison of average yields despite BM differences of each individual patient, show that stability of operator performance varies significantly (see Tables 2 and 3.)

\section{Conclusion}

Operator performance seems can affect cell and tissue processing yields. Processing performance analysis show - no significant differences between operators were found, except minor differences in buffy coat transfer. Operator B transfer nearly all plasma phase, operator A leave approximately $1 \mathrm{ml}$ of plasma phase over density gradient layer.

Sample size is too small to prove statistical significance of finding, more data is needed to study buffy coat transfer impact on cell extraction efficacy.

\section{Acknowledgements}

This study was supported in part by Latvian National Research Program "Biomedicine for Public Health" (BIOMEDICINE) and by grant from corporation "Sistemu Inovacijas".

\section{References}

[1] Giuseppe, A., Sabrina, S., Viviana, L. C., Francesco, S., Daniel, S., Lucia, T., Gianni, S., Tiziano, M. 2010. "Bone Marrow Derived Stem Cells in Regenerative Medicine as Advanced Therapy Medicinal Products." Am. J. Transl. Res. 2 (3): 285-95.

[2] Lachtermacher, S., Esporcatte, B. L., da Silva de Azevedo, F., Rocha, N. N., Montalvao, F., et al. 2012. Functional and Transcriptomic Recovery of Infracted Mouse Myocardium Treated with Bone Marrow Mononuclear Cells." Stem Cell Rev. 8: 251-61.
[3] Korf-Klingebiel, M., Kempf, T., Sauer, T., Brinkmann, E., Fischer, P., et al. 2008. "Bone Marrow Cells Are a Rich Source of Growth Factors and Cytokines: Implications for Cell TherapyTrials after Myocardial Infarction." Eur. Heart J. 29: 2851-8.

[4] Lunde, K., Solheim, S., Aakhus, S., Arnesen, H., Abdelnoor, M., et al. 2006. "Intracoronary Injection of Mononuclear Bone Marrow Cells in Acute Myocardial Infarction." N. Engl. J. Med. 355: 1199-209.

[5] Schachinger, V., Erbs, S., Elsasser, A., Haberbosch, W., Hambrecht, R., et al. 2006. "Intracoronary Bone Marrow-Derived Progenitor Cells in Acute Myocardial Infarction.” N. Engl. J. Med. 355: 1210-21.

[6] Strauer, B. E., Brehm, M., Zeus, T., Kostering, M., Hernandez, A., et al. 2002. "Repair of Infarcted Myocardium by Autologous Intracoronary Mononuclear Bone Marrow Cell Transplantation in Humans." Circulation 106: 1913-8.

[7] Clifford, D. M., Fisher, S. A.,Brunskill, S. J., Doree, C., Mathur, A.,Watt, S., and Martin-Rendon, E. 2012. "Stem Cell Treatment for Acutemyocardial Infarction." Cochrane Database of Systematic Reviews 2.

[8] Matoba, S., Tatsumi, T., Murohara, T., Imaizumi, T., Katsuda, Y., et al. 2008. "Longterm Clinical Outcome after Intramuscular Implantation of Bone Marrow Mononuclear Cells (Therapeutic Angiogenesis by Cell Transplantation [TACT] Trial) in Patients with Chronic Limb Ischemia." Am. Heart J. 156: 1010-8.

[9] Leri, A., Kajstura, J., Anversa, P., and Frishman, W. H. 2009. "Myocardial Regeneration and Stem Cell Repair." Current Problem in Cardiology 33: 91-153.

[10] Bartunek, J., Vanderheyden, M., Hill, J., and Terzic, A. 2010. "Cells as Biologics for Cardiac Repair in Ischaemic Heart Failure.” Heart 96: 792-800.

[11] Aktas, M., Radke, T. F., Strauer, B. E., Wernet, P., and Kogler, G. 2008. "Separation of Adult Bone Marrow Mononuclear Cells Using the Automated Closed Separation System Sepax." Cytotherapy 10: 203-11.

[12] Florian, H. S., Torsten, T., Nicola, K., Andreas, M. Z., and Stefanie, D. 2007. "Cell Isolation Procedures Matter: A Comparison of Different Isolation Protocols of Bone 
198 Bone Marrow Mononuclear Cell Extraction. Does the Operator Performance Affect Processing Efficacy?

Marrow Mononuclear Cells Used for Cell Therapy in Patients with Acute Myocardial Infarction.” European Heart Journal 28: 766-72

[13] Van Beem, R. T., Hirsch, A., Lommerse, I. M., Zwaginga, J. J., Noort, W. A., et al. 2008. "Recovery and
Functional Activity of Mononuclear Bone Marrow and Peripheral Blood Cells after Different Cell Isolation Protocols Used in Clinical Trials for Cell Therapy after Acute Myocardial Infarction." Euro. Intervention 4: 133-8. 